\title{
Chironomid midges (Diptera: Chironomidae) emerged from bottom sediments in the deep lake, Lake Sai, Japan
}

\author{
Kimio Hirabayashi ${ }^{*}{ }^{1)}$, Zhenghai $\mathrm{Fu}^{1)}$, Kazuya Yoshizawa ${ }^{2)}$, \\ Norihiko Yoshida $^{3)}$, Futaba KazAma ${ }^{4)}$ \\ * Corresponding author: Department of Applied Biology, Shinshu University, \\ 3-15-1, Tokida, Ueda, Nagano, 386-8567 Japan \\ (E-mail: kimio@shinshu-u.ac.jp) \\ 1) Department of Applied Biology, Shinshu University, 3-15-1, Tokida, Ueda, Nagano, 386-8567 Japan \\ 2) Yamanashi Institute for Public Health, 1-7-31, Fujimi, Kofu, Yamanashi, 400-0027 Japan \\ 3) Yamanashi Prefectural University, 5-11-1, Iida, Kofu, Yamanashi, 400-0035 Japan \\ ${ }^{4)}$ University of Yamanashi, 4-3-11, Takeda, Kofu, Yamanashi, 400-8511 Japan
}

(Received: 12 May 2011; Accepted: 26 June 2011)

\begin{abstract}
The chironomid fauna in the deep lake, Lake Sai, Japan, was investigated in March, 2009. Thirteen ( 8 males and 5 females) chironomid midges were collected with a sweeping net around the boat house and 81 (44 males and 37 females) chironomid midges emerged in the laboratory. They were identified as 11 species belonging to four subfamilies, i.e., 7 species of Chironominae, 1 species of Orthocladiinae, 1 species of Prodiamesinae and 2 species of Tanypodinae. At the deepest Station 4 (65.5 $\mathrm{m}$ in depth), we could not collect chironomid midges. However, only Micropsectra chuzeprima Sasa, 1984 was collected at Station $5(56.6 \mathrm{~m})$. At Stations $6(29.6 \mathrm{~m})$ and $3(18.8 \mathrm{~m})$, two species, M. chuzeprima and Procladius choreus (Meigen, 1804), were collected. On the other hand, at the shallowest Station $1(4.9 \mathrm{~m})$, we collected nine chironomid species, and the most numerous species in this collection was Polypedilum nubeculosum (Meigen, 1804) with a total of 41 individuals collected. In previous reports, a total of 16 species were collected from around the lake. We additionally describe 10 species from Lake Sai in this study. Only one species, $P$. nubeculosum, was common to the earlier report and the present study. As a result, there are 26 species recorded from Lake Sai.
\end{abstract}

Key words: bathymetric distribution, chironomid fauna, deep lake, Lake Sai, rearing, water depth

\section{INTRODUCTION}

Lake Sai $\left(35^{\circ} 30^{\prime} \mathrm{N}, 138^{\circ} 41^{\prime} \mathrm{E}\right.$ at the center of the lake; surface area $2.17 \mathrm{~km}^{2}$; maximum depth $73.2 \mathrm{~m}$; mean depth $38.5 \mathrm{~m}$; altitude above sea level $901.5 \mathrm{~m}$ ) is located at the north foot of Mt. Fuji (Fig. 1). Lake Sai has four inflowing small streams and only one outlet used for power generation (Fig. 1). The basin is steep and shallow bottoms consist mainly of shattered rocks, lava and sand. Therefore, there are few aquatic plants in the shallow regions ( $5 \mathrm{~m}$ depth $>$ ). Aizaki et al. (1981) ranked this lake as an oligotrophic lake with the modified Carlson's trophic state index (TSI) based on chlorophyll- $a$, total phosphorus and transparency.

Many limnological studies have been carried out in this lake since the first intensive work by Tanaka (1910). Tanaka (1992) reviewed the studies of Lake Sai, including water quality, zooplankton, phytoplankton, benthos, fishes and aquatic macrophytes. In 2010, 70 years after extinction from Lake Tazawa, Akita Prefecture, "Kunimasu", Oncorhynchus kawamurae (Pisces: Salmonidae) was rediscovered from this lake (Nakabo, 2011). However, there have been few studies 




Fig. 1. Maps showing the location of Lake Sai, isopleths of depth ( $\mathrm{m}$ ), and sampling stations in the lake (collected by sweeping around the boat house; solid triangle, and larval rearing; Stations 1-7).

on the chironomid fauna (Miyadi, 1932; Kitagawa, 1973). The purpose of this paper is to record the chironomid fauna in the deep lake, Lake Sai. Therefore, chironomid fauna were investigated by collecting samples from seven stations of varying depths on March 8, 2009 and were reared in the laboratory.

\section{Materials and Methods}

Chironomid larvae can be gathered most efficiently from late autumn to early spring, when most larvae, especially $P$. akamusi (Yamagishi and Fukuhara, 1972), come close to the surface of the sediment (Brinkhurst, 1974). On March 8, 2009, bottom sediment samples were collected at seven stations of varying depths (4.9-65.5 $\mathrm{m}$ depth; Fig. 1) from Lake Sai with a standard Ekman-Birge grab $(15 \times 15 \mathrm{~cm})$. The sampling points were determined by a global positioning system (GPS). These samples were transported to our laboratory under cool conditions and then transferred to separate transparent plastic containers $(24 \mathrm{~cm}$ in diameter and $11 \mathrm{~cm}$ in height) with adequate water collected from Lake Sai. Moderate aeration was 


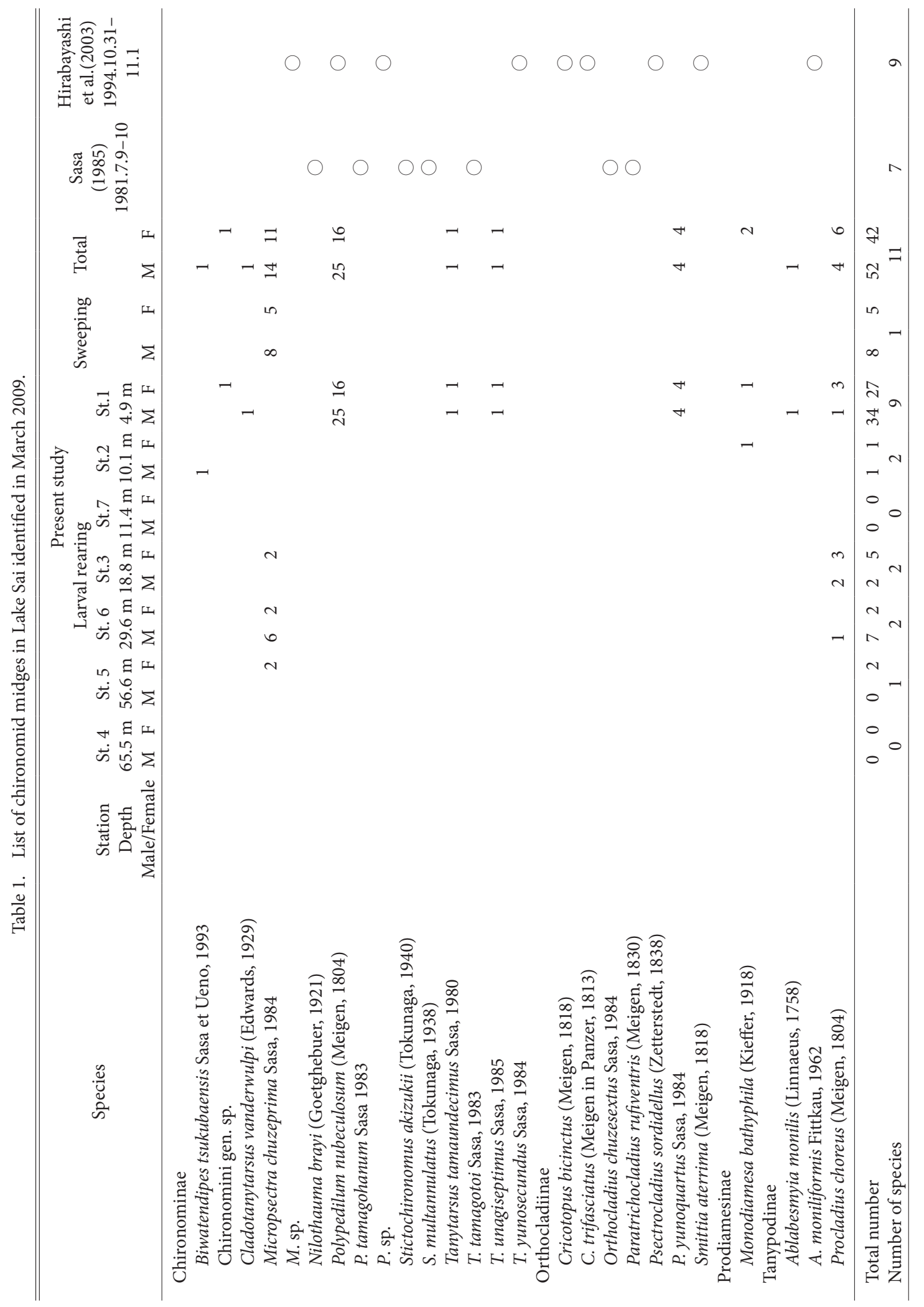


supplied during rearing with a diaphragm pump through an air stone. Each container was covered with fine nylon net fixed with a rubber band to prevent escape of emerging adults. The samples were reared at room temperature $\left(10-20^{\circ} \mathrm{C}\right)$, higher than at the collection site, to facilitate emergence. Additional food was not supplied during rearing because the sediment sample contained enough detritus as food for the chironomid larvae. Emerging adults and pupal exuviae were checked and collected every day for about three months, 15 days after the last emergence ceased. Adults were preserved as dried specimens and only males were used for identification because of the difficulty in accurate identification of females and immature stages. Males were mounted on slides with gum chloral under a binocular dissecting microscope (max. x 40), examined under a high-powered biological microscope (max. $x 600)$ and identified to species using taxonomical keys by Pinder (1978), Wiederholm (1989), Sasa and Kikuchi (1995) and Sæther et al. (2000).

In addition, chironomid midges were also collected with a sweeping net from around the boat house on the northeast shore of this lake from 7 to 8 of March, 2009 (see Fig. 1).

\section{Results and Discusstion}

Table 1 shows the list of chironomid midges from Lake Sai. A total of 94 (52 males and 42 females) chironomid midges were collected. Thirteen (8 males and 5 females) chironomid midges were collected by sweepingnet around the boat house (Fig. 1) and 81 (44 males and 37 females) chironomid midges emerged in the laboratory. They were identified as 11 species belonging to four subfamilies, i.e., 7 species of Chironominae, 1 species of Orthocladiinae, 1 species of Prodiamesinae and 2 species of Tanypodinae. At the deepest Station 4 (65.5 $\mathrm{m}$ in depth), we could not collect chironomid midges. However, at Station 5 (56.6 m), only Micropsectra chuzeprima Sasa, 1984 was collected. At Stations $6(29.6 \mathrm{~m})$ and $3(18.8 \mathrm{~m})$, two species, M. chuzeprima and Procladius choreus (Meigen, 1804), were collected. On the other hand, at the shallower Station $1(4.9 \mathrm{~m})$, we collected nine chironomid species and the most numerous species in this collection was Polypedilum nubeculosum (Meigen, 1804) with a total of 41 individuals collected. In addition, $P$. choreus was also collected from Station 1, indicating this species is able to inhabit a wide range of depths from 29.6 to $4.9 \mathrm{~m}$. According to Ali (1995), P. nubeculosum and P. choreus were nuisance species, i.e., reported to emergence in massive swarms from a variety of habitats in various countries of the world (Cranston, 1988). These species should be closely monitored for future trends. At the sweeping site, only $M$. chuzeprima chironomid midges were collected, indicating the investigation period was at the time of $M$. chuzeprima emergence.

In previous reports, a total of 16 species were collected from around the lake (Sasa, 1985; Hirabayashi et al., 2003). We additionally describe a total of 10 species in this study from Lake Sai. Only one species, P. nubeculosum, was common to the earlier report of Hirabayashi et al. (2003) and the present study. As a result, there are 26 species recorded from Lake Sai.

The chironomid species in the shallow regions $(5 \mathrm{~m}$ water depth $>$ ) of Lake Sai were few (Table 1), especially the chironomid fauna inhabiting aquatic plants, compared with the other Fuji Five Lakes (Hirabayashi et al., 2003). Johnson et al. (1993) and Saji et al. (2004) reported that chironomid communities of the littoral zone are affected by many factors such as substrate, water chemistry and macrophytes. According to Hirabayashi and Nakamoto (2001), an area with aquatic plants supports the largest number of chironomid species and constitutes the most important habitat. Therefore, the abundance and types of vegetation are considered to influence the diversity of chironomid assemblages. Tanaka (1992) reported the macrophytes of this lake are very few because the shore is steep. This may be a reason for the collection of few species from the littoral zone.

\section{ACKNOWLEDGEMENTS}

The authors thank Eiso Inoue (Department 
of Applied Biology, Shinshu University) for help with the field and laboratory work.

\section{REFERENCES}

Aizaki, M., Otsuki, A., Fukushima, T., Kawai, T., Hosomi, M. and Muraoka, K. 1981. Application of modified Carlson's trophic state index to Japanese lakes and its relationships to other parameters related to trophic state (in Japanese with English summary). Res. Rep. Nat. Inst. Environ. Stud. 23: 13-31.

Ali, A. 1995. Nuisance, economic impact and possibilities for control. In: The Chironomidae. The biology and ecology of non-biting midges (eds. Armitage, P. D., Cranston, P. S. and Pinder, L. C. V.), pp. 339-364, Chapman \& Hall, London.

Brinkhurst, R. O. 1974. The benthos of lakes. 190 pp. The Macmillan Press Ltd., London.

Cranston, P. S. 1988. Allergens of non-biting midges (Diptera: Chironomidae): a systematic survey of chironomid hemoglobin. Med. Vet. Entomol. 2: 117-127.

Hirabayashi, K. and Nakamoto, N. 2001. Studies on Chironomidae in waterfronts: current status and future prospects. Jpn. J. Ecol. 51: 23-40 (in Japanese).

Hirabayashi, K., Yamamoto, M., Yoshida, N. and Sasa, M. 2003. Newly identified chrionomids at Fuji Five Lakes in the fall season. Med. Entomol. Zool. 54: 389-394.

Johnson, R. K., Wiederholm, T. and Eriksson, L. 1993. Classification of littoral macroinvertebrate communities of Swedish reference lakes. Int. Verh. Ver. Limnol. 25: 512-517.

Kitagawa, N. 1973. Studies on the bottom fauna of The Fuji Five Lakes and Lake Ashino. Rikusui Fueiyouka no Kisotekikenkyu. 2: 32-37. (in Japanese)

Miyadi, D. 1932. Studies on the bottom fauna of Japanese lakes. 5. Five Lakes at the north foot of Mt. Hudi and Lake Asi. Jpn. J. Zool., 4: 81-125.

Nakabo, T. 2011. "Kunimasu" Oncorhynchus kawamurae (Pisces: Salmoidae), 70 years after extinction in Lake Tazawa, Akita Prefecture, Japan. Taxa, 30: 31-54.

Pinder, L. C. V. 1978. A key to adult males of British Chironomidae, 169 pp. with figs., Freshwater Biological Assoc. Publ. No. 37, Windermere Laboratory, The Ferry House, Ambleside, Cumbria, England.

Sæther, O. A., Ashe, P. and Murray, D. A. 2000, Family Chironomidae. In: Contributions to a manual of $\mathrm{Pa}$ laearctic Diptera, Appendix. (eds. Papp, L. and Darvas, B.), pp. 113-334, Science Herald, Budapest.

Saji. A., Nakazato, R., Sakurai, H., Sakuma, M. and Hanazato T. 2004. Population dynamics of epiphytic chironomid communities in the aquatic macrophytes zones of eutrophic Lakes Suwa and Kitaura. Rep. Res. Edu. Ctr. Inlandwat. Environ. 2: 111-115.

Sasa, M. 1985. Studies on chironomid midges of some lakes in Japan. Res. Rep. Nat. Inst. Environ. Stud. 83: 101-160.

Sasa, M. and Kikuchi, M. 1995. Chironomidae (Diptera) of Japan. 334 pp. University of Tokyo Press, Tokyo.

Tanaka, A. 1910. On Nishino-Umi. Suisann Kenkyushi 5: 200-220. (in Japanese)

Tanaka, M. 1992. The Lakes in Japan. 530 pp., Nagoya University Press, Nagoya.

Wiederholm, T. 1989. Chironomidae of the Holarctic region. Keys and Diagnoses. Part 3. Adults. Entomol. Scand. Suppl. 34: 1-532.

Yamagishi, H. and Fukuhara, H. 1972. Vertical migration of Spaniotoma akamusi larvae (Diptera: Chironomidae) through the bottom deposits of Lake Suwa. Jpn. J. Ecol. 22: 226-227. 